\title{
Study on Formation Mechanism of Dumping Piles on Dumping Area Stability
}

\author{
Donghua Zhang, Naoya Inoue, Takashi Sasaoka, Hideki Shimada, Akihiro Hamanaka, \\ Kikuo Matsui \\ Department of Earth Resources Engineering, Faculty of Engineering, Kyushu University, Fukuoka City, Japan \\ Email: zhang10r@mine.kyushu-u.ac.jp
}

Received 20 February 2014; revised 15 March 2014; accepted 23 March 2014

Copyright (C) 2014 by authors and Scientific Research Publishing Inc.

This work is licensed under the Creative Commons Attribution International License (CC BY). http://creativecommons.org/licenses/by/4.0/

\section{Open Access}

\begin{abstract}
Dumping areas represent a stable hazard. To clarify the formation mechanism of dumping piles on dumping area stability, an investigation in open pit mine was performed. Moreover, experiments with gravel were conducted based on the research site conditions. The geological conditions, dumping operation, and waste particle size distribution were investigated in the Heidaigou open pit mine. Particle size distribution, dumping height, dumping volume, and floor inclination were varied to examine their effects on a single pile formation. The design of blasting can be modified to make the particle size of waste smaller. The volume of the bucket does not have a pronounced effect on dumping pile repose angle, capacity of dumping pile, and dumping area stability. The smaller the floor inclination, the better it is. Two measures are proposed to increase the kinetic force of friction between waste material and floor surface. The interval distance, dumping volume and dumping height were also varied to examine the interaction between the formations of multiple piles. The dumping width should be decided through optimization efficiency of bulldozer and dumping device in bucket wheel excavator-belt-stacker dumping operation and dragline dumping operation. Moreover, the volume of the bucket does not have a pronounced interaction effect. In the dumping operation, the work amount of bulldozer decreases as dumping pile increases. The design of the dumping operation must consider the total efficiency of ground leveling operation and forming dumping the area.
\end{abstract}

\section{Keywords}

Open Pit Mine, Dumping Pile, Formation Mechanism, Site Investigation, Experiment

\section{Introduction}

Dumping work is an important component of open pit mining [1]-[4]. Under overburden, stripped and waste 
rocks or soils are transported to dumping areas to expose and extract coal seams. Waste embankments typically have little if any practical use and may represent a long-term liability as a potential pollution source or stability hazard [5]-[7].

In 1978, China initiated reforms and opening-up policies. Moreover, in 1986, the first internal dumping area was founded in the Yimabei open pit mine. In 1987, the first large-scale Antaibao open pit mine was established in Shuozhou City, Shanxi province. Subsequently, many large-scale open pit mines were established (Table 1).

After 2002, heavy industry growth became obvious in China. Coal output increased from 1.72 to 3.24 billion tons from 2003 to 2010 [8] (Table 2). Numerous open pit mines were established or expanded.

Currently, high slopes and large-scale dumping areas are formed and will be formed. Slope and dumping area stability has become important. Moreover, the slope and dumping areas are stable hazards for mining operations. Because of stability risks, waste dumps must be carefully designed. However, systematic studies on dumping area stability are limited, and large-scale landslides continue to occur in dumping areas [9]-[11]. At present, more effort must be implemented to design appropriate dumping areas that control stability risks.

To clarify the formation mechanism of dumping piles on dumping area stability, an investigation in open pit mine and experiments with gravel were conducted. In the Heidaigou open pit mine, the geology overview, dumping operation, waste particle distribution, problems were investigated. In the laboratory, a series of experiments were conducted to simulate the formation process of single dumping pile, and multiple dumping piles, and the efficiency of dumping operation design.

\section{Field Investigations}

Field investigations are useful to govern dumping sites [12]-[15]. The Heidaigou open pit mine is located in the Inner Mongolia Autonomous Region, China (Figure 1). In 2011, raw coal output was 31 million tons (Mt). The recoverable reserve was $1093 \mathrm{Mt}$. This open pit mine has one internal, and 5 external dumping areas.

\subsection{Geology Overview of Heidaigou Open Pit Mine}

The studied open pit mine on the Erdos Plateau is relatively high in the northwest and low in the southwest; the maximum and minimum elevations are 1365.5 and $870 \mathrm{~m}$, respectively. The height difference is $595.5 \mathrm{~m}$. Gen-

\begin{tabular}{|c|c|c|c|}
\hline $\begin{array}{l}\text { Representative } \\
\text { Mines }\end{array}$ & Design capability (Mt/a) & First production year & Open pits \\
\hline Antaibao & 22 & 1987 & 3 \\
\hline Huolinhe & 8 & 1992 & 2 \\
\hline Yiminhe & 5 & 1998 & 3 \\
\hline Yuanbaoshan & 10 & 1989 & 2 \\
\hline Shengli-1 & 20 & 2007 & 5 \\
\hline Xiaolongtan & 4.8 & 1995 & 2 \\
\hline Hongshaquanbei & 3 & 2010 & $\geq 7$ \\
\hline Baiyinhua-1 & 15 & 2005 & 4 \\
\hline Hedaigou & 23 & 1999 & 2 \\
\hline
\end{tabular}

Table 2. Total raw coal output and consumption from 2003 to 2010.

\begin{tabular}{cccc}
\hline Year & Production (billion tons) & Year & Production (billion tons) \\
2003 & 1.72 & 2007 & 2.53 \\
2004 & 1.99 & 2008 & 2.80 \\
2005 & 2.20 & 2010 & 3.97 \\
2006 & 2.37 & 209 & 3.24 \\
\hline
\end{tabular}




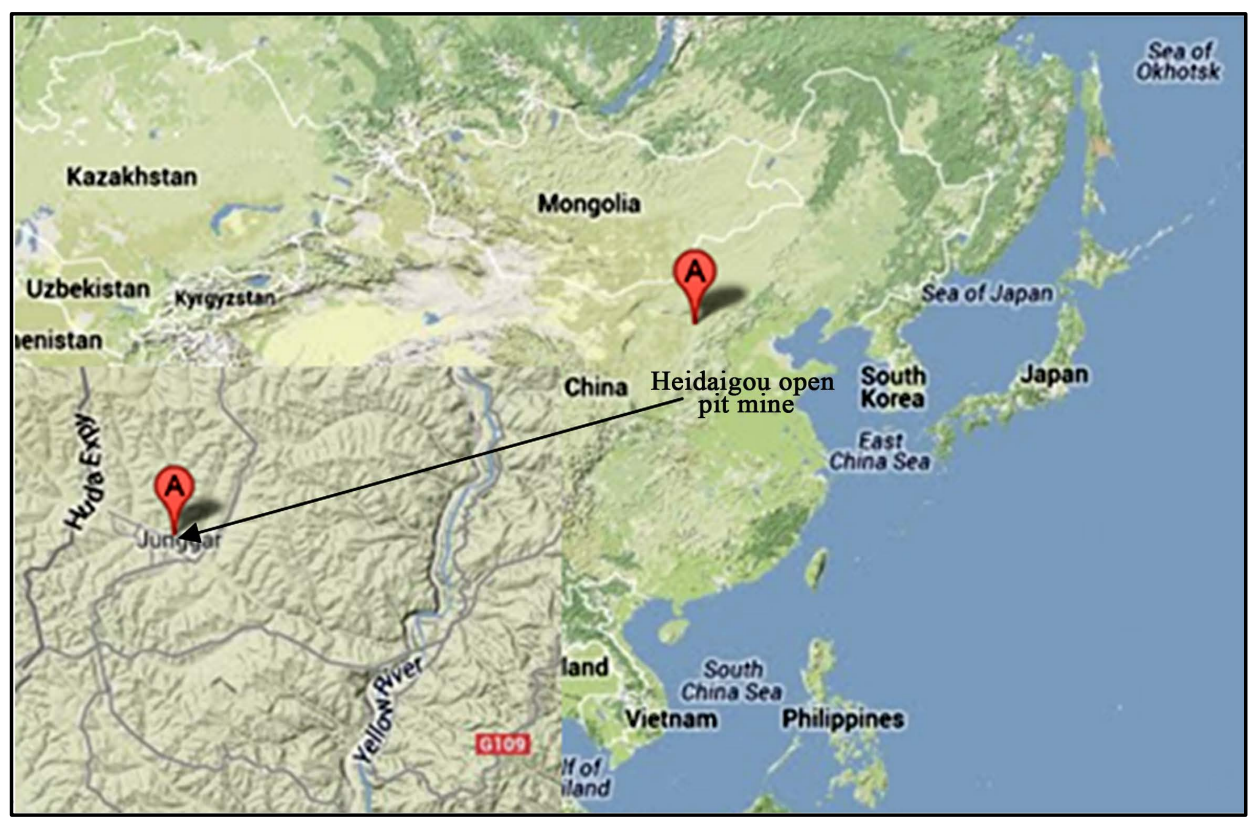

Figure 1. Location of the Heidaigou open pit mine.

erally, the elevation ranges from $1100 \mathrm{~m}$ to $1300 \mathrm{~m}$. Figure 2 provides an overview of the Heidaigou open pit mine.

The annual precipitation ranges from 231 to $634.7 \mathrm{~mm}$. The annual average precipitation is $408 \mathrm{~mm}$. The annual evaporation ranges between 1324.7 and $2896.1 \mathrm{~mm}$, with an annual average of approximately $2100 \mathrm{~mm}$. The climate is arid around the open pit mine. The coal seam floor elevation is higher than the Yellow River water table elevation. There are two primary drainage mechanisms. One way is through natural infiltration, and the other is natural evaporation. The water has a small effect on the dumping stability in the Heidaigou open pit mine.

The limiting strike length for mining is $7.8 \mathrm{~km}$. The average mine width at the bottom is $5.09 \mathrm{~km}$; the area is $40.25 \mathrm{~km}^{2}$, and the average depth is $150 \mathrm{~m}$.

Table 3 shows the soil and rock physical-mechanical properties in the Heidaigou open pit mine.

\subsection{Dumping Operation of Heidaigou Open Pit Mine}

The Heidaigou open pit mine utilizes three dumping operation types. These operations include bucket wheel excavator-belt-stacker dumping, shovel-truck-bulldozer dumping, and dragline dumping operation.

\subsubsection{The Bucket Wheel Excavator-Belt-Stacker Dumping Operation}

Loess is present at the top of the overburden. The bucket wheel excavator-belt-stacker dumping operation (Figure 3 ) is used to remove the overburden. In these dumping benches, the waste is primarily loess and contains only small amounts of rock. The particle size distribution is very small and uniform. The waste soils are dumped from the stacker to the slope top, which then roll along the bench slope. Bulldozers adjust the bench top. Table 4 shows the main parameters for bucket wheel excavator-belt-stacker dumping in the internal dumping area.

\subsubsection{The Shovel-Truck-Bulldozer Dumping Operation}

Various rocks are found in the middle of the overburden. The shovel-truck-bulldozer (Figure 4) dumping operation is used to remove the overburden. In these benches, the major waste is sandstone, mudstone, and clay stone. The particle size distribution varies widely. Generally, small blocks are centralized in the top bench and large blocks are located in the bottom bench. The waste rocks are dumped from the truck to the ground surface and slope. Moreover, waste materials roll from the slope top to bottom. Bulldozers push the remaining materials from the ground surface to the slope. Table 5 shows the main parameters for shovel-truck dumping in the internal dumping area. 
Table 3. Soil and rock physical-mechanical properties in the Heidaigou open pit mine.

\begin{tabular}{cccc}
\hline Sample name & Density $\left(\mathrm{Kg} / \mathrm{m}^{3}\right)$ & Angle of internal friction (degree) & Cohesion $(\mathrm{KPa})$ \\
\hline Loess & 1950 & 29.5 & 45.1 \\
Mudstone & 2440 & 30.0 & 1275.3 \\
Sandy mudstone & 2450 & 30.0 & 2256.3 \\
Packsand & 2450 & 31.0 & 3237.3 \\
Medium sandstone & 2270 & 31.5 & 2452.5 \\
Gritstone & 2240 & 32.0 & 1760 \\
Contain gravel gritstone & 2260 & 33.0 & 3924 \\
Coal & 1400 & 35.0 & 1851 \\
\hline
\end{tabular}

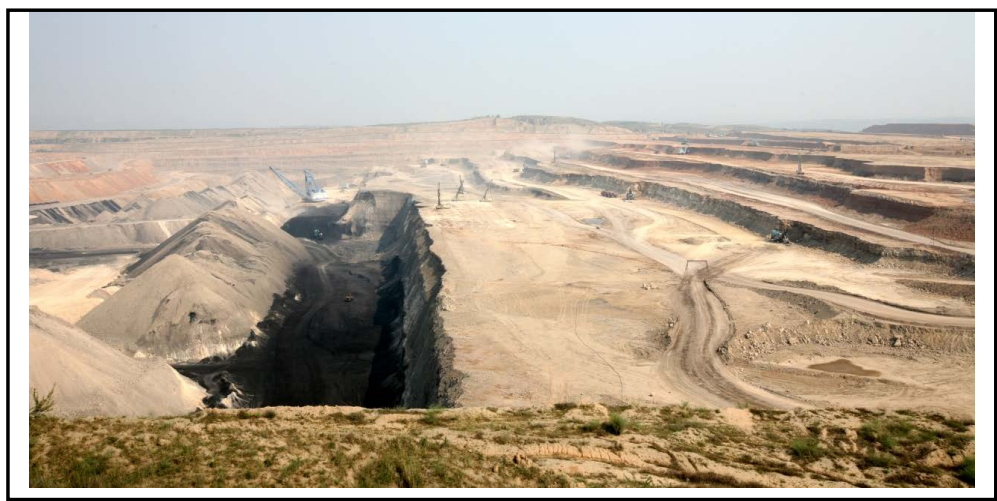

Figure 2. Overview of the Heidaigou open pit mine.

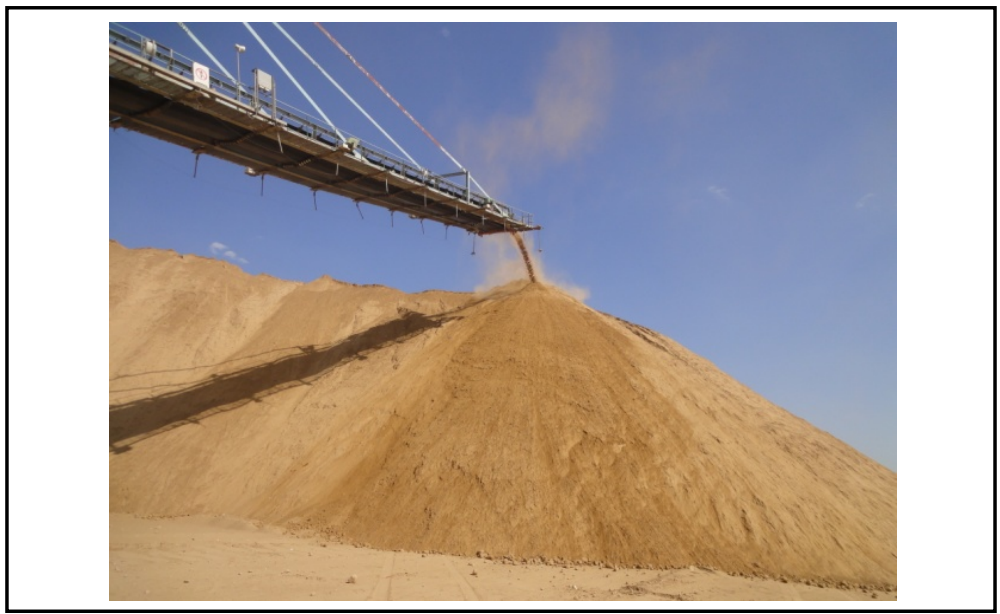

Figure 3. Bucket wheel excavator-belt-stacker dumping operation in the dumping area.

\subsubsection{The Dragline Dumping Operation}

At the overburden bottom, dragline dumping (Figure 5) is used to remove the overburden. The particle size distribution is similar to the shovel-truck-bulldozer dumping operation. The waste rocks are dumped from dragline bucket to the slope top, which then roll along the slope. The dumping height is approximately 88 m. Moreover, the dumping pile is not compacted, and the dumping pile base is a floor of coal seams. Table 6 shows the main parameters for dragline dumping in the internal dumping area. 
Table 4. Main parameters for bucket wheel excavator-belt-stacker dumping in the internal dumping area.

\begin{tabular}{cccccc}
\hline Parameters & Unit & Value & Parameters & Unit & Value \\
\hline Bench height & Meter & 18 & Minimum bench working width & Meter & 120 \\
Dumping height & Meter & 20 & Final slope angle of slope & Degree & 20 \\
Dumping width & Meter & 40 & Factor of loose & & 1.15 \\
\hline
\end{tabular}

Table 5. The parameters for shovel-truck-bulldozer dumping in the internal dumping area.

\begin{tabular}{ccccc}
\hline Parameters & Unit & Value & Parameters & Unit \\
Bench height & Meter & 35 & Final slope angle & Degree \\
Rock roll distance & Meter & 18 & Minimum working width & Meter \\
Repose angle & Degree & $35-38$ & Factor of loose & 1.2 \\
\hline
\end{tabular}

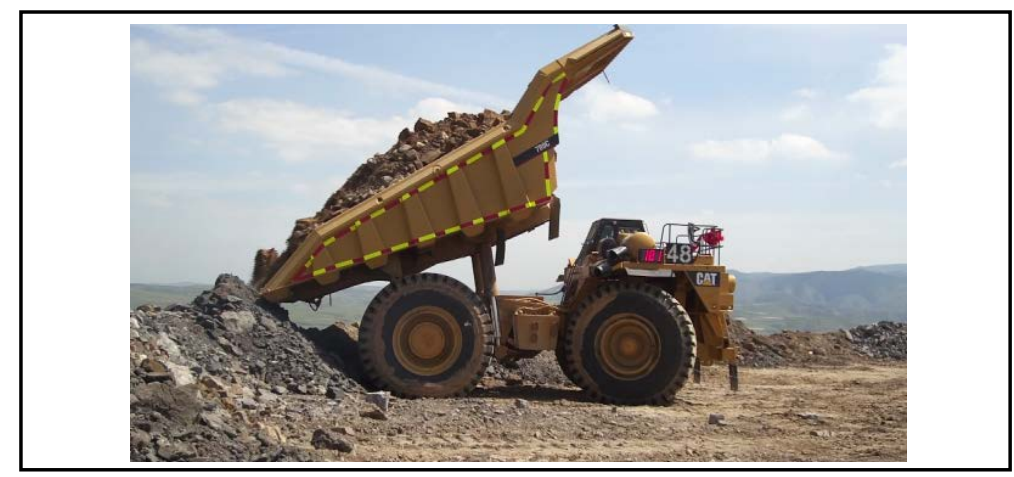

Figure 4. Shovel-truck-bulldozer dumping operation in the internal dumping area.

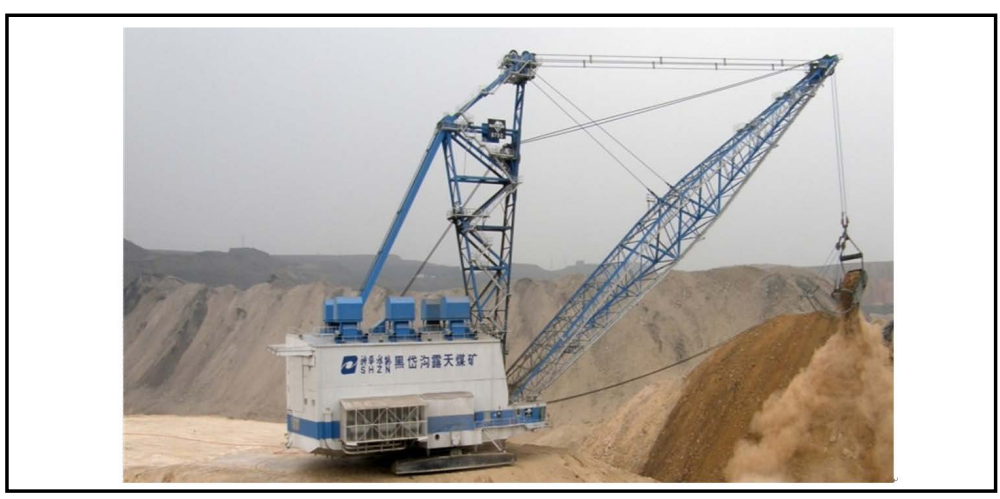

Figure 5. Dragline dumping operation in the internal dumping area.

\subsection{Waste Particle Size Distributions}

We selected 7 pictures from separate benches in the shovel-truck-bulldozer and dragline dumping areas. The waste particle size distribution is analyzed with Spilt-Desktop Version 2.0 software. Table 7 shows the waste particle size distribution analysis results for the shovel-truck-bulldozer and dragline dumping areas.

\subsection{Problems Statement of Heidaigou Open Pit Mine}

The dumping area problems in the Heidaigou open pit mine are as follows.

1) For excavator-belt-stacker dumping, the operation efficiency is low. 
Table 6. Main parameters for dragline dumping in the internal dumping area.

\begin{tabular}{cccccc}
\hline Parameters & Unit & Value & Parameters & Unit & Value \\
\hline Average bench height & Meter & 60.8 & Coal bench angle & Degree & 75 \\
Bench height & Meter & 72.5 & Dumping pile angle & Degree & 38 \\
Bench width & Meter & 80 & Blasted stockpile settlement height & Meter & 13.5 \\
Average dumping pile height & Meter & 60.8 & Blasted stockpile height & Meter & 31.5 \\
Factor of loose & & 1.35 & Efficiency throwing coefficient & Percent & 25 \\
Coal bench height & Meter & 30 & Coal road width & Meter & 30 \\
Rock bench angle & Degree & 65 & & & \\
\hline
\end{tabular}

Table 7. Waste particle size distribution analysis results for the shovel-truck-bulldozer and dragline dumping areas.

\begin{tabular}{ccccc}
\hline Material No. & P20 $(\mathrm{mm})$ & P50 $(\mathrm{mm})$ & P80 $(\mathrm{mm})$ & Top size $(\mathrm{mm})$ \\
\hline 1 & 88.7 & 177.1 & 362.1 & 642.4 \\
2 & 109.9 & 199.2 & 300.0 & 524.4 \\
3 & 151.4 & 264.7 & 393.9 & 577.9 \\
4 & 91.4 & 146.7 & 293.2 & 565.5 \\
5 & 143.1 & 274.0 & 539.8 & 845.4 \\
7 & 186.0 & 302.9 & 482.1 & 800.6 \\
Average & 114.7 & 215.0 & 368.0 & 664.7 \\
\hline
\end{tabular}

Note: P20-Corresponds to the size in which $20 \%$ of the total mass is represented by smaller particles. P50-Corresponds to the size in which $50 \%$ of the total mass is represented by smaller particles. P80-Corresponds to the size in which $80 \%$ of the total mass is represented by smaller particles.

2) For shovel-truck-bulldozer dumping, the principal waste is loess in the Yinwan external dumping area. The dumping area is next to a reservoir with extensive subsidence. Therefore, large trucks cannot work in this area (Figure 6) because it is a potential safety risk to both the workers and equipment.

3) For dragline dumping, the bench height is $75 \mathrm{~m}$. Small landslides occur frequently and affect the safety of workers and equipment (Figure 7).

\subsection{Methodology}

Experimental tests are useful to prove and verify theories [16]-[18]. Experiments were conducted to clarify the mechanism of dumping pile formation.

Figure 8 provides an overview of the experimental device. A certain volume sample is dumped from a specified height with a constant initial velocity. Then, the pile shape is measured. To maintain a constant frictional force at the floor surface, a felt mat is placed on the plate surface. The particle size distribution, dumping volume, dumping height, floor angle, and interval distance can be set in the device.

The experimental procedures are as follows.

1) Select a group of samples that correspond to a particle size range with a sieve;

2) Measure a constant volume sample with a graduated cylinder;

3) Place the constant volume samples into the bucket;

4) Set the dumping height and floor angle;

5) Start the crane and dump them on the floor with a constant initial velocity;

6) Measure the pile height, length, width, and angle;

7) Repeat 2) through 6) 5 times. Record data and calculate averages.

Figure 9, Figure 10 and Figure 11 show the measurement process in the experimental tests. 


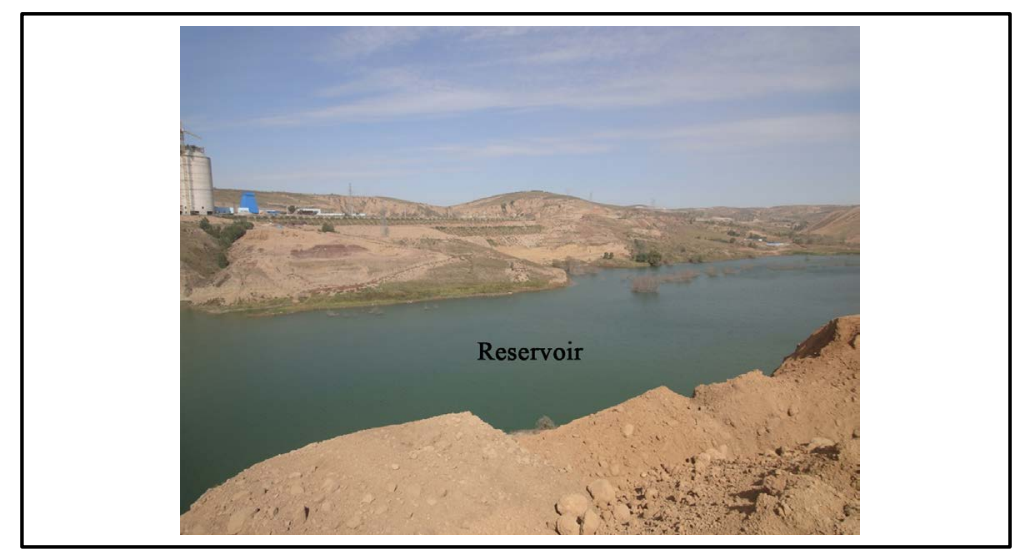

Figure 6. Yinwan external dumping area next to a reservoir.

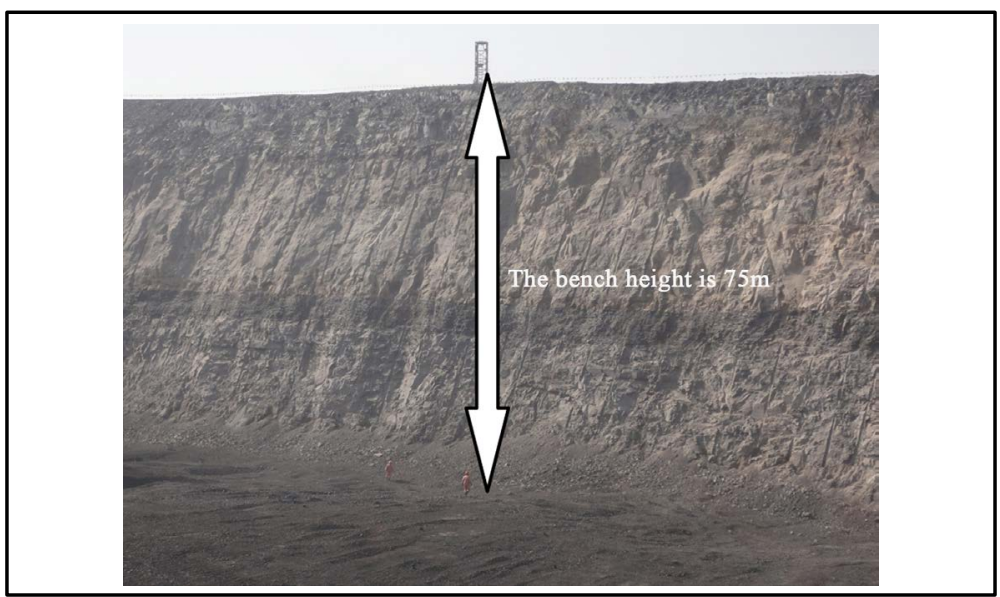

Figure 7. High working slope bench in a dragline operation.

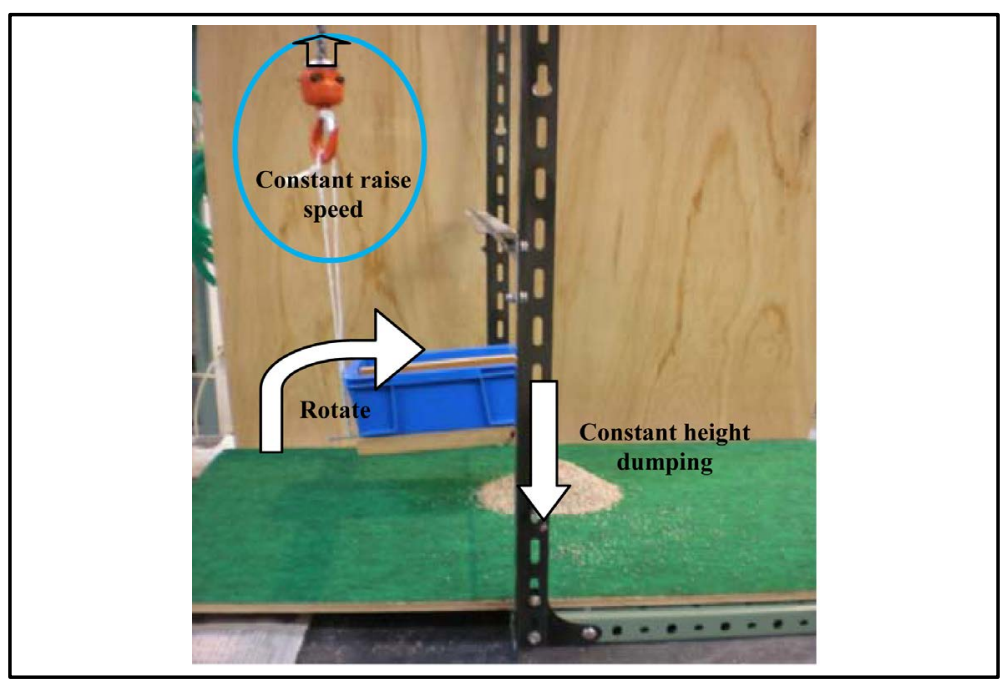

Figure 8. Overview of the experimental device.

At first, the effects of particle size, dumping height and drop volume on the formation of single dumping pile were discussed. Secondly, multiple dumping piles are formed and then the interaction between adjacent dumping piles was discussed under different interval distances. In order to eliminate the effect of water contents of 


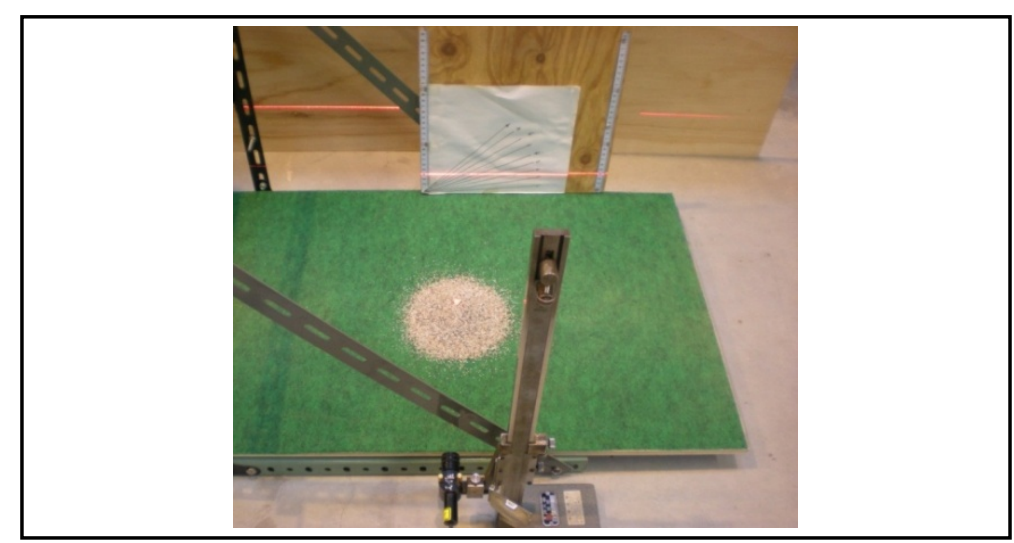

Figure 9. Process to measure the height.

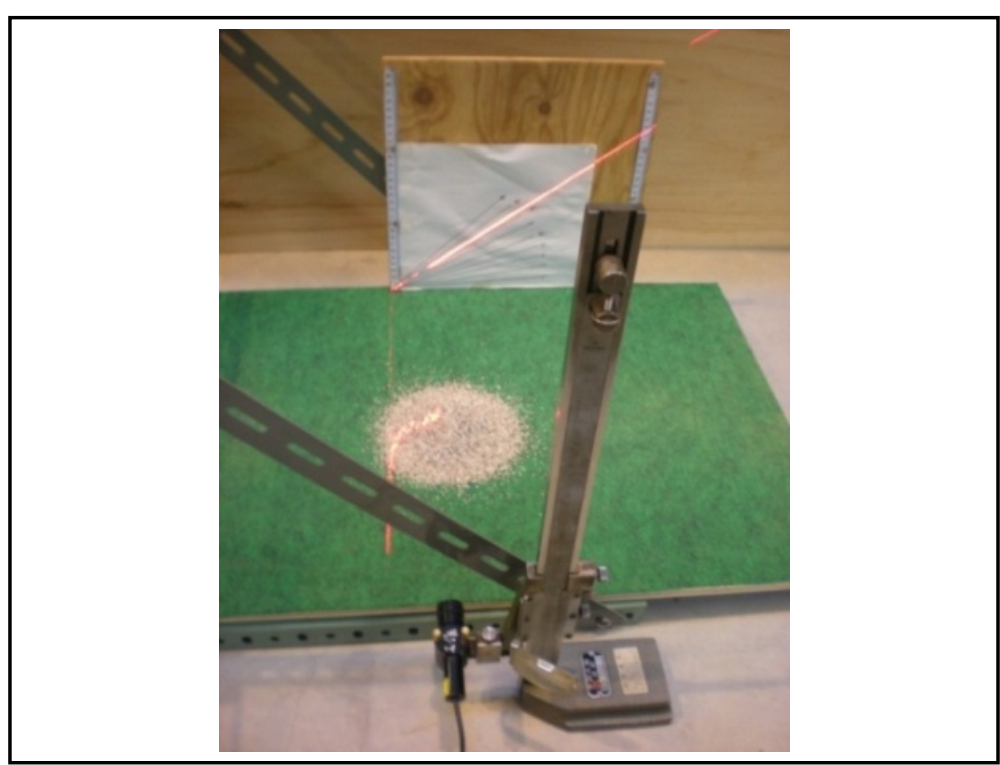

Figure 10. Process to measure the repose angle.

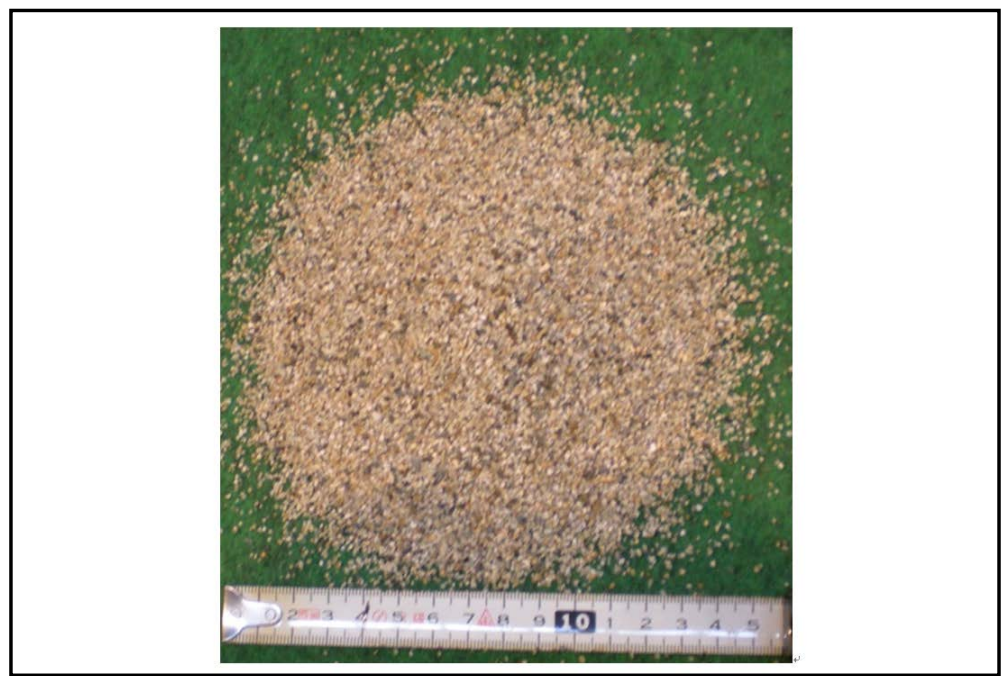

Figure 11. Process to measure the length and width. 
samples, all samples are dried before the test. Gravel and coarse sand were used in this test as the waste materials. Scale factor was set as 80 based on the results of field investigations and the condition of laboratory test. The average values of P20, P50, and P80 are converted to $1.58 \mathrm{~mm}, 2.82 \mathrm{~mm}$, and $4.89 \mathrm{~mm}$, respectively. According to the opening of standard sieve, the particle sizes of samples are set from $1.00-1.68 \mathrm{~mm}, 1.68-2.83$ $\mathrm{mm}$ and $2.83-4.75 \mathrm{~mm}$. A certain volume of a sample was dropped from a certain height to the floor and then the dimension of the pile was measured. A felt mat was laid on the floor in order to maintain the frictional force between dumping pile/waste materials and floor constant. In this device, drop volume, drop height, drop rate and floor angle can be controlled.

\section{Experiment Methods and Results}

\subsection{Single Dumping Pile}

At first, effects of a particle size, a drop height, a drop volume, and a dip of foundation on the formation of single dumping pile are discussed.

\subsubsection{Effect of a Particle Size and a Drop Height on the Shape of Dumping Pile}

The relationship between the pile height/slope angle of dumping pile and the drop height under different particle sizes of waste materials are shown in Figure 12 and Figure 13, respectively. Slope angle is angle of repose of the dumping pile.

Figure 12 and Figure 13 show that the larger the particle size is, the lower the dumping pile height is and the smaller the slope angle is. It can be said that the larger the particle size is the more weight the dropping material is and more inertia force they have, so the materials are well spread.

They also show that the higher the drop height is, the lower the dumping pile height is and the smaller the slope angle is. The velocity of dropping material when it reaches at the top of the pile increases with the increase of drop height. As a kinetic force of friction is fixed, dropping material rolled the slope faster and reached farther away. Moreover, as their impact force also increases with the increase of drop height, waste material was compacted and the bench height was decreased.

From the above results, it can be concluded that both particle size and dropping height have an obvious impact on the formation of dumping pile.

Based on above laboratory tests and site investigation, the following conclusions were found:

1) The design of blasting can be changed to make the particle size of waste smaller. In the dumping area, the dumping pile repose angle decreases and the roll distance of rock increase as the particle size of the waste in-

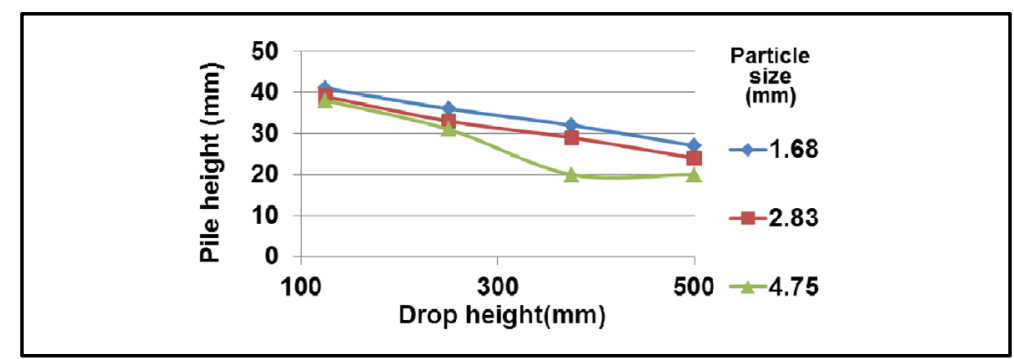

Figure 12. Relationship between pile height and drop height.

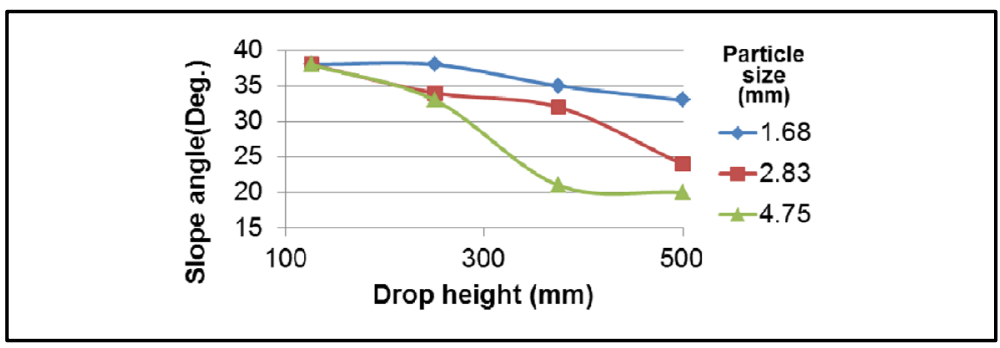

Figure 13. Relationship between slope angel and drop height. 
crease. As the dumping pile repose angle decreases, the capacity of dumping pile and dumping area stability decreases. Moreover, as the roll distance of rock increases, the safety distance by rock roll increases.

2) The capacity of dumping pile is maximized and the safety distance by rock roll is minimized in the bucket wheel excavator-belt-stacker dumping operation. The value of shovel-truck dumping operation is in the midlevel. The capacity of dumping pile is minimized and the safety distance by rock roll is maximized in the dragline dumping operation.

\subsubsection{Effect of a Drop Volume on the Shape of Dumping Pile}

The relationship between the pile height/slope angle and the drop volume of sample are shown in Figure 14.

It can be seen from this figure that the pile height increases with increasing the drop volume. However, there are no obvious changes on the slope angle and the bench shape due to the change of drop volume.

Hence, it can be said that a drop volume do not have an obvious impact on the shape of dumping pile.

\subsubsection{Effect of Floor Dip on the Shape of Dumping Pile}

Table 8 shows the shape of dumping pile under different dip of floor. Pile length is a length of tendency direction; pile width is a length of strike direction. Figure 15 shows length, height and repose of angle of dumping pile. It can be seen from Table 8 that the pile height and angle of repose decreases with increasing dip of floor. However, obvious change of the shape cannot be seen in angle of repose. The larger the dip of floor is, the faster the waste material roll along the surface of the floor. As the results, the pile length increases and the pile height decreases with increasing the dip of floor.

Based on the above laboratory tests and site investigation, the following measures were found:

1) In the selection process of dumping area, the smaller the floor inclination, the better. The dumping pile height decreases and dumping pile length increase as floor inclination increases. Moreover, as the floor inclination increases, the capacity of dumping pile decrease and the roll distance of rock increase.

2) Some measures should be taken to increase the kinetic force of friction between waste material and floor surface. The kinetic force of friction between waste material and floor surface is no more than the kinetic force of friction between waste material and waste material. It is easy to be a weak seam. Generally the inclined floor is flat and an entirety surface, it is easy to be a slide surface. For instance, in the treatment process of floor, we can remove the loose earth and all vegetation to make the floor strong seam. Some pits can be formed in the floor's surface with blasting method to make the floor not easy to be a slide surface.

\subsection{Multiple Dumping Piles}

Next, the formations of multiple dumping piles were investigated under different conditions. Figure 16 and Figure 17 show the diagram of dumping order and drop interval distance and that of pile height and their difference, respectively.

Figure 18 shows the relationship between an increase of the pile height and a pile number under different drop intervals. Pile numbers indicates the first, second, third, fourth and fifth dumping pile. Here, the increase of the pile height means the difference between the height of each dumping pile and that of first one. It represents that the height of dumping pile increases with the increase of pile number. The height of dumping pile increases gradually and then becomes to be a constant. Moreover, the shorter the drop interval is, the higher the dumping pile is.

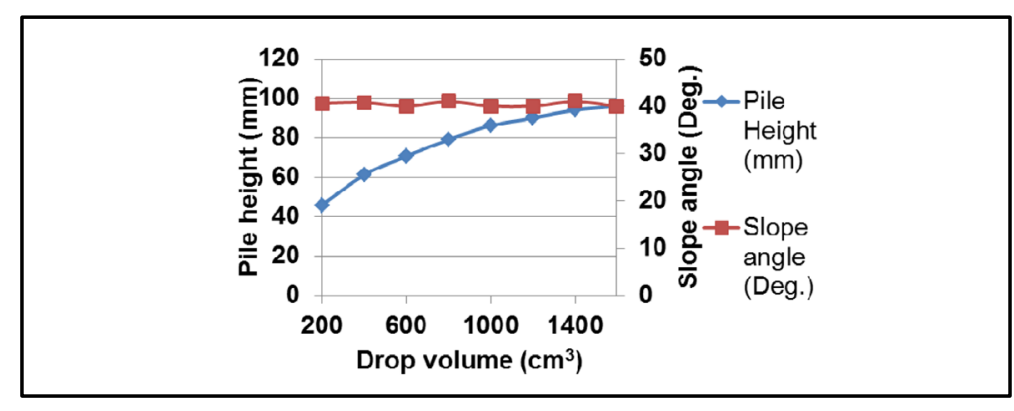

Figure 14. Relationship between pile height/slope angle and drop volume. 
D. Zhang et al.

Table 8. Relation between floor inclination and dumping pile shape.

\begin{tabular}{|c|c|c|c|c|c|}
\hline \multirow{2}{*}{ Dip of foundation (degree) } & Pile height & Angle of repose 1 & Angle of repose 2 & Pile length & Pile width \\
\hline & $(\mathrm{mm})$ & (degree) & (degree) & $(\mathrm{mm})$ & $(\mathrm{mm})$ \\
\hline 20 & 32 & 37 & 21 & 155 & 145 \\
\hline 15 & 37 & 39 & 23 & 145 & 145 \\
\hline 10 & 40 & 40 & 30 & 140 & 140 \\
\hline 5 & 41 & 40 & 32 & 140 & 145 \\
\hline 0 & 40.5 & 38 & 36 & 143 & 153 \\
\hline
\end{tabular}

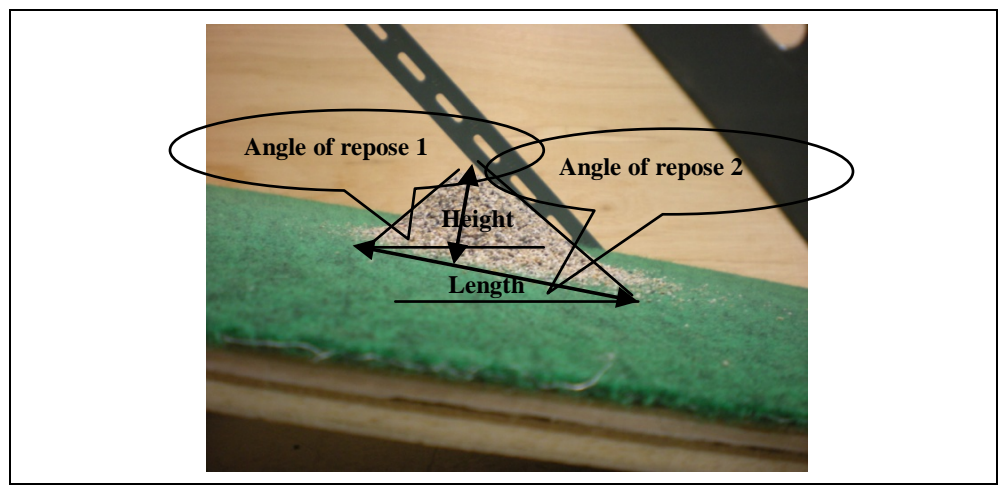

Figure 15. Diagram of length, height and repose of angle of dumping pile.

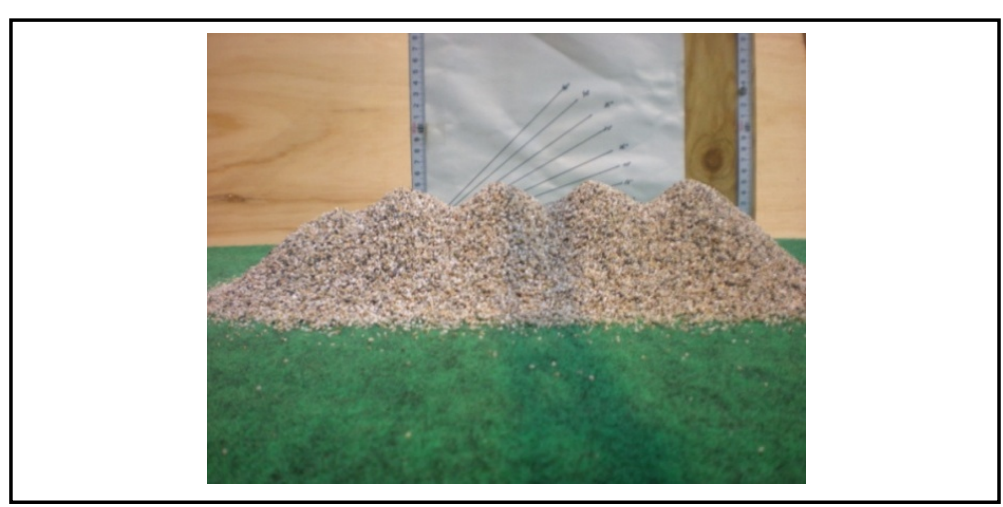

Figure 16. Diagram of dumping order and interval distance.

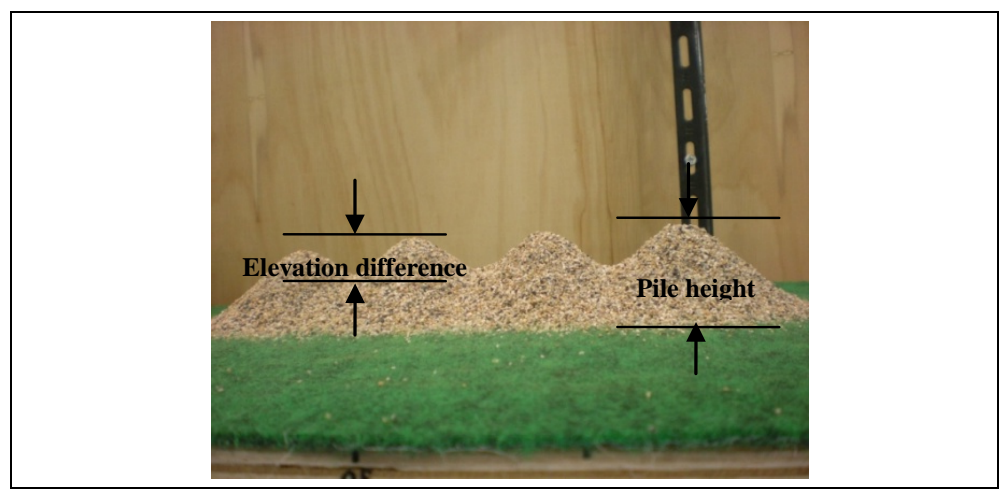

Figure 17. Diagram of elevation difference and pile height measurements. 


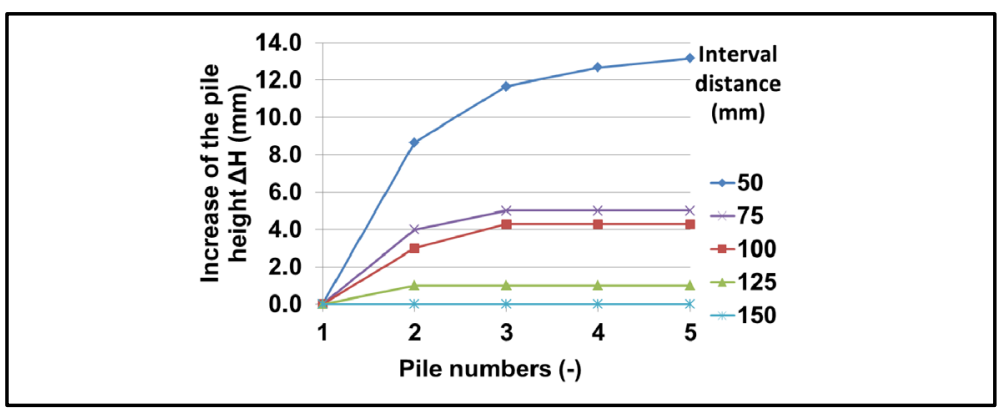

Figure 18. Relationship between the increase of pile height and the pile number.

Based on the above laboratory tests and site investigation, the following conclusion was found. The dumping width should be decided through optimization efficiency of bulldozer and dumping device in bucket wheel excavator-belt-stacker dumping operation and dragline dumping operation. The interaction decreases as the dumping width increases. The work amount of bulldozer increases as the interaction decreases. Efficiency of dumping device decreases as dumping width decreases in bucket wheel excavator-belt-stacker dumping operation and dragline dumping operation.

Figure 19 shows the relationship between the increase height of fifth pile and drop intervals under different drop volumes. It represents the height of dumping pile increases with decreasing intervals under all drop volumes. When interval distance reaches to a specific one at each drop volume, no interaction between neighboring piles are observed. This is because of the interference between two adjacent piles. As the drop interval decreases, the interference of previous dumping pile on the next one appears and becomes to be large.

In the dumping operation, the volume of bucket does not have a pronounced interaction effect on dumping operation. The pile height increases and the minimum interval distance increases as dumping volume increases. Meanwhile, the ratio of dumping volume to dumping pile volume is too small.

Figure 20 represents that the relationship between the ratio of the increase height and the ratio of the interval of drop point to volume. Here, the ratio of the increase of height represents that the increase height of fifth pile is divided by the height of the first pile. The ratio of the dropping interval is that the dropping interval is (I) divided by the cubic root of volume $\left(\mathrm{V}^{1 / 3}\right)$.

Figure 20 shows that the similar tendencies of height increase despite of drop volume. Thus, the pile height can be estimated by the following equation.

$$
\Delta H / H_{o}=-0.260 \ln \left(I / V^{1 / 3}\right)+0.800
$$

From the above discussions, it can be concluded that in the dumping operation the work amount of bulldozer decreases as dumping pile increases. The pile height decreases and interaction effect increases as dumping height increases. Meanwhile, the work amount of bulldozer decreases as interaction effect increases.

\subsection{Efficiency of Dumping Operation Design}

Land reclaiming must be carried out after dumping work. Figure 21 shows the process of ground leveling operation work. It is necessary to grade dumping piles with bulldozer. Therefore, the elevation difference and pile numbers are measured to examine the amount of grading work under different dumping conditions.

At first, we measure the elevation difference of the fifth dumping pile. Figure 22 shows the relationship between elevation difference and interval distance. Figure 22 shows that the elevation difference increases as the interval distance increases. Therefore, it is believed that the elevation difference of dumping pile decreases as the interval distance decreases. The amount of grading work decreases as the elevation difference of dumping pile decreases. The cost reduction of the ground leveling operation is possible.

Second, the volume of each pile was changed to examine the relationship between pile numbers and amount of grading under the condition of constant total volume and constant floor area. An example of the results is shows that in Table 9. It shows that the amount of grading increases as the pile numbers increases. The result shows that the work amount of grading operation decreases as the dumping volume of equipment decreases. 


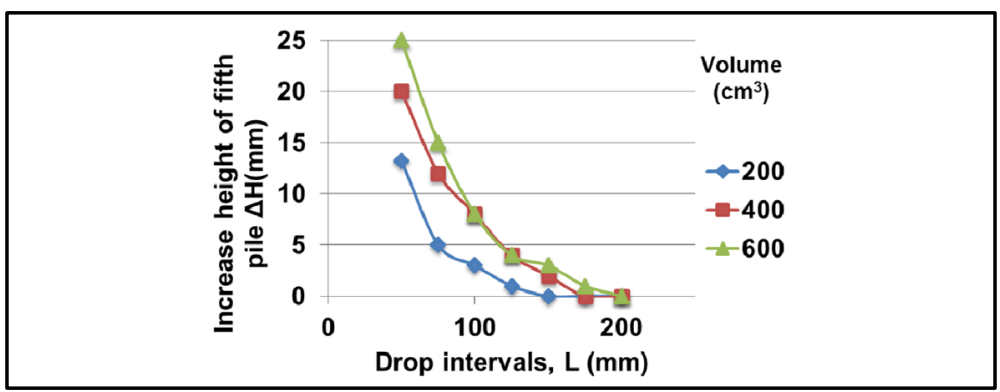

Figure 19. Relationship between the increase height of the fifth pile and drop interval.

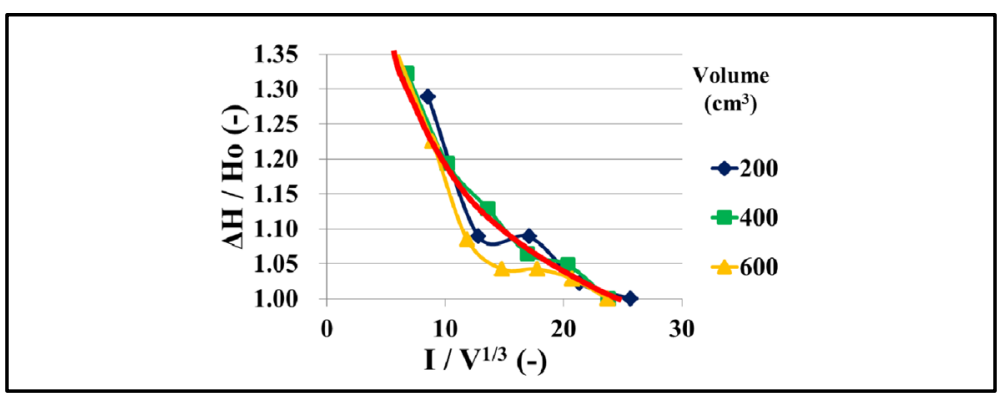

Figure 20. Ratio of increase height-ratio of interval of drop point to volume.

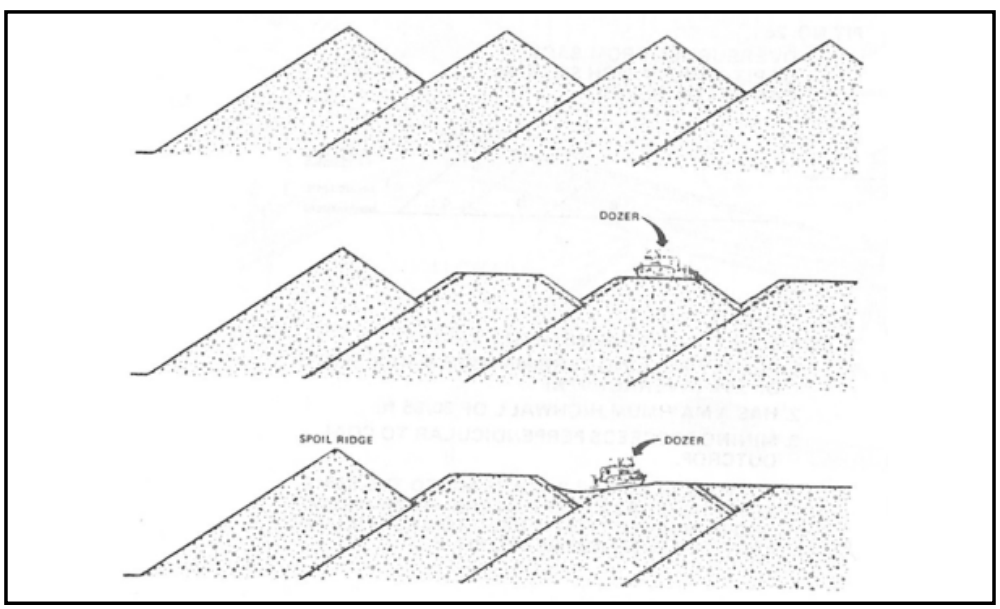

Figure 21. Process of ground leveling operation work.

Second, the volume of each pile was changed to examine the relationship between pile numbers and amount of grading under the condition of constant total volume and constant floor area. An example of the results is shows that in Table 9. It shows that the amount of grading increases as the pile numbers increases. The result shows that the work amount of grading operation decreases as the dumping volume of equipment decreases.

However, different equipment has different efficiency, different flexibility, and bucket volume. Equipment will decide the dumping volume, cost, the work time of building the dumping pile and stripping work. Therefore, the design of the dumping operation must consider the total efficiency of ground leveling operation and forming dumping area.

\section{Conclusions}

In this study, a site investigation and a series of experiments were performed to determine the formation mechanisms of dumping piles and slope stability. The following conclusions were found: 
Table 9. Relationship between the amount of grading work and pile numbers.

\begin{tabular}{ccccc}
\hline Total volume $\mathrm{V}_{0}\left(\mathrm{~cm}^{3}\right)$ & \multicolumn{3}{c}{1200} & \\
\hline Pile numbers & 6 & 4 & 2 & 1 \\
Floor area $\mathrm{A}\left(\mathrm{cm}^{2}\right)$ & & 570 & & 461.1 \\
Amount of grading $\Delta \mathrm{V}\left(\mathrm{cm}^{3}\right)$ & 81.53 & 160.8 & 197.6 & \\
\hline
\end{tabular}

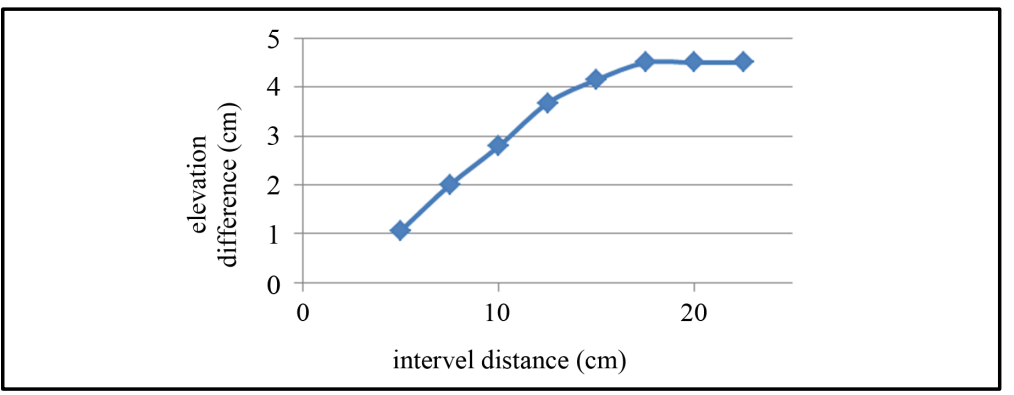

Figure 22. Relationship between the elevation difference and interval distance $\left(200 \mathrm{~cm}^{3}\right)$.

Based on site investigations at the Heidaigou open pit mine, different dumping operations have different operational and geotechnical issues. In the bucket wheel excavator-belt-stacker dumping area, the operation efficiency is low. Moreover, in the shovel-truck-bulldozer dominant loess dumping area, substantial subsidence exists. Large trucks cannot work in this area. In the dragline dumping area, the bench height is high; small landslides occur frequently, affecting the safety of staff and equipment.

The design of blasting can be changed to make the particle size of waste smaller. In the dumping area, the capacity of dumping pile decreases and safety distance by rock roll increase as the particle size of the waste increases. The capacity of dumping pile is maximized and the safety distance by rock roll is minimized in the bucket wheel excavator-belt-stacker dumping operation. The value of shovel-truck dumping operation is in the midlevel. The capacity of dumping pile is minimized and the safety distance by rock roll is maximized in the dragline dumping operation. The volume of bucket does not have a pronounced effect on dumping pile repose angle, capacity of dumping pile, and dumping area stability. In the selection process of dumping area, the smaller the floor inclination, the better it is. Two methods are proposed to increase the stability of dumping areas. First, the loose earth and all vegetation can be removed to make the floor strong seam. Second, floor surface of dumping area becomes rough by blasting, which can prevent the floor from being slide surface.

The dumping width should be decided through optimization efficiency of bulldozer and dumping device in bucket wheel excavator-belt-stacker dumping operation and dragline dumping operation. In the dumping operation, the volume of bucket does not have a pronounced interaction effect on dumping operation. In the dumping operation, the work amount of bulldozer decreases as dumping pile increases. The design of the dumping operation must consider the total efficiency of ground leveling operation work and forming dumping area work.

\section{Acknowledgements}

The authors wish to express appreciation for the assistance and cooperation given by the G-COE.

\section{References}

[1] Kennedy, B.A. (1990) Surface Mining. 2nd Edition, Society for Mining, Metallurgy, and Exploration, Indonesia, 890.

[2] Wang, G.J., Kong, X.Y. and Gu, Y.L. (2011) Research on Slope Stability Analysis of Super-High Dumping Area Based on Cellular Automaton. SREE Conference on Engineering Modelling and Simulation, 12, 248-253. http://www.sciencedirect.com/science/article/pii/S1877705811009532

[3] Golder, H.Q. (1976) The Stability of Natural and Man-Made Slope in Soil and Rock. Geotechnical Practice for Stability in Open Pit Mining, Chapter 6, 79-85. 
[4] Blight, G. (2008) Slope Failures in Municipal Solid Waste Dumps and Landfills: A Review. Waste Management \& Research, 26, 448-463. http://dx.doi.org/10.1177/0734242X07087975

[5] Huang, M., Li, X., et al. (2007) Analysis of Stability of Waste-Dump Slope of a Mine. Mining and Metallurgical Engineering, 3.

[6] Luo, R.M. (1995) Repose Angles and Rock Size Distributions of Yinziyu Waste Dump. Mining and Metallurgical Engineering.

[7] Byrnes, P., Färe, R., et al. (1988) The Effect of Unions on Productivity: US Surface Mining of Coal. Management Science, 34, 1037-1053. http://dx.doi.org/10.1287/mnsc.34.9.1037

[8] National Bureau of Statistics of China in 2012 (2013) China Statistics Yearbook. China Statistics Press, Beijing, 7-1.

[9] Kocasoy, G. and Kriton, C. (1995) The Ümraniye-Hekimbaşi Open Dump Accident. Waste Management \& Research, 13, 305-314.

[10] Koelsch, F., Fricke, K., Mahler, C., et al. (2005) Stability of Landfills-The Bandung Dumpsite Disaster. Proceedings Sardinia.

[11] Huvaj-Sarihan, N. and Stark, T.D. (2008) Back Analyses of Landfill Slope Failures. Proceedings of 6th International Case Histories Conference, 11-16. http://tstark.net/wp-content/uploads/2012/10/CP85.pdf

[12] Siegel, R.A., Robertson, R.J. and Anderson, D.G. (1990) Slope Stability Investigations at a Landfill in Southern. Geotechnics of Waste Fills: Theory and Practice, 1070, 259.

[13] Xie, X. and Pang, C.H. (2003) Fractal Characteristic of Size Distribution of Bulky Rock Material in Waste Dump of Open Pit Mines.

[14] Costa, J.E. and Schuster, R.L. (1988) The Formation and Failure of Natural Dams. Geological Society of America Bulletin, 100, 1054-1068. http://dx.doi.org/10.1130/0016-7606(1988)100<1054:TFAFON>2.3.CO;2

[15] Machado, S.L. and Karimpour-Fard, M. (2010) Evaluation of the Geotechnical Properties of MSW in Two Brazilian Landfills. Waste Management, 30, 2579-2591.

[16] Bellaloui, A., Chtaini, A., et al. (1999) Laboratory Investigation of the Control of Acid Mine Drainage Using Alkaline Paper Mill Waste. Water, Air, and Soil Pollution, 111, 57-73. http://dx.doi.org/10.1023/A:1005017912012

[17] Krahn, J., Fredlund, D.G. and Klassen, M.J. (1989) Effect of Soil Suction on Slope Stability at Notch Hill. Canadian Geotechnical Journal, 26, 269-278. http://dx.doi.org/10.1139/t89-036

[18] Pelkey, S.A., Valsangkar, A.J. and Landva, A. (2001) Shear Displacement Dependent Strength of Municipal Solid Waste and Its Major Constituent. ASTM Geotechnical Testing Journal, 24, 381-390.

http://dx.doi.org/10.1520/GTJ11135J 